\title{
Telicity and the Meaning of Objective Case ${ }^{\square}$
}

\author{
Angelika Kratzer \\ University of Massachusetts at Amherst \\ December 2002
}

\section{Introduction}

The link between telicity and accusative case has inspired much syntactic work and is also well documented in the semantic literature. Gillian Ramchand made the case for Scottish Gaelic, for example, and Paul Kiparsky for Finnish (Ramchand 1997, Kiparsky 1998). In this chapter, I will suggest that the same connection between telicity and accusative case can be detected in German, and probably in English as well. I will start out by presenting a syntactic and semantic analysis of the telicity effects associated with accusative in Finnish. Using Finnish as a guide, I will then introduce techniques for observing the same effects in German, where they are hidden and easy to overlook, since the language has no systematic choices for how it case-marks direct objects.

According to Kiparsky 1998, case for direct objects in Finnish is determined at the VP level. Direct objects have partitive case if their VP is 'unbounded' and accusative case if their VP is 'bounded'1:

प. I thank Jacqueline Guéron and Jacqueline Lecarme for organizing the conference where this paper was presented. Jacqueline Guéron also sent substantial comments that led to a complete makeover of the paper. For crucial feedback at crucial moments I'd like to thank Lisa Matthewson, who challenged the applicability of an earlier account to Salish, Ji-Yung Kim, who did the same for Russian, and in particular Roger Schwarzschild, who sent generous written notes, and whose work on the Grammar of Measurement had quite an impact on the very final version. The paper is much indebted to the pioneering works of Paul Kiparsky, Gillian Ramchand and Anne Vainikka. 
(1)

a. Ammu - i - n karhu - a. Partitive shoot - past -1sg bear - part I shot at a bear.

I shot at the bear.

b. Ammu-i-n karhu-n. Accusative shoot - past - 1sg bear - acc

I shot the bear.

I shot a bear.

a. Ammu - i - n karhu -j-a. Partitive shoot - past - 1sg bear - pl - part

I shot bears.

I shot at bears.

I shot at the bears.

b. Ammu - i - n karhu - t. Accusative shoot - past - 1sg bear - pl - acc I shot the bears.

a. Ammu - i - n kah-ta karhu - a. Partitive shoot - past - 1sg two-part bear - part. I shot at two bears.

I shot at the two bears.

b. Ammu - i-n kaksi karhu-a Accusative shoot - past - 1sg two-acc. bear - part I shot two bears. I shot the two bears.

Why should there be a connection between a semantic property of VPs and case morphology on direct objects? Where in the grammar could the link between, say, boundedness and accusative case even be stated? I will explore the idea that the connection between case and telicity might be provided by minimalist views on interpretable and non-interpretable features: Verbal inflectional features might be the interpretable counterparts of uninterpretable case features (Chomsky 1995,

1. (1) to (3) are from Kiparsky 1998, p. 267, but are arranged differently. 
2001, Pesetsky \& Torrego 2001). If there are verbal inflectional heads

corresponding to telicity, the relation between objective case and telicity is agreement. An uninterpretable feature [acc] on DPs agrees with its interpretable counterpart, a verbal inflectional feature linked to telicity. A major consequence of this proposal is that the telicity of a large class of verbs is now syntactically constructed. While differing in detail, the analysis proposed here builds on and confirms an important insight that Ramchand 1997 reached on the basis of Scottish Gaelic. According to Ramchand, the "claim here is that the notion of 'verb' is not a unified one, but consists of two logically separate constituents: a substantive core and an aspectual head. The parametric variation between languages consists in the different ways in which these two separate functions are morphologically instantiated."2

\section{What an interpretable [acc] feature could do: A proposal}

While a syntactician might not think twice about positing an interpretable feature [acc] that is identical to [telic], such an assumption causes considerable headaches to the semanticist. She is expected to come up with a hypothesis about what that feature is supposed to do. She has to put a proposal on the table about the semantic division of labor between bare verb stems and an inflectional head linked to telicity, and is facing Zucchi's problem of indirect access at that point (Zucchi 1999). Take accomplishment verbs. Suppose they are built from stems that have event arguments ranging over activities and processes. But in addition to describing those activities as, say, climbs or moves, they might also tell us something about where those events are headed to. A climb, for example, may aim for the top of Mount Monadnock. Using terminology from Parsons 1990, the stems of accomplishment verbs might determine the culmination conditions for the events they describe. I suggest we distinguish between culmination conditions and culmination requirements. Determining the conditions for culmination does not yet

2. Ramchand 1997, p. 169. 
imply culmination. The conditions merely state what has to be the case if the events in question culminate. The feature [telic], could now invariably add the requirement that culmination occur. For illustration, here are two sample entries for accomplishment stems and a possible denotation for interpretable [acc] (= $[\text { telic] })^{3}$ :

$$
\begin{array}{ll}
\text { Shoot- } & \square \mathrm{x} \square \mathrm{e}[\operatorname{shoot}-\operatorname{at}(\mathrm{x})(\mathrm{e}) \&[\operatorname{culminate}(\mathrm{x})(\mathrm{e}) \square \operatorname{hit}(\mathrm{x})(\mathrm{e})]] \\
\text { Climb- } & \square \mathrm{x} \square \mathrm{e}[\operatorname{climb}-\mathrm{up}(\mathrm{x})(\mathrm{e}) \&[\operatorname{culminate}(\mathrm{x})(\mathrm{e}) \square \operatorname{climb} \text {-to(top-of } \mathrm{x})(\mathrm{e})]] \\
\text { [telic] } & \square \mathrm{R} \square \mathrm{x} \square \mathrm{e}[\mathrm{R}(\mathrm{x})(\mathrm{e}) \text { \& culminate(x)(e)] }
\end{array}
$$

Following Marantz 1984, Kratzer 1996, and Pylkkänen 2002, external arguments are not taken to be arguments of their verbs in (4). Transitive verbs express relations between individuals and events. In the case of climb, for example, the relation holds between an individual $\mathrm{x}$ and an event e just in case e is an event of climbing up $\mathrm{x}$. The culmination condition for climb says that the event e culminates with respect to $\mathrm{x}$ just in case $\mathrm{e}$ is an event in which the top of $\mathrm{x}$ is reached. The denotation of [telic] is a function that can apply to the denotations of verbs like climb. Its only job is to require that the events described by the verb culminate with respect to the referent of the direct object argument. Applied to the denotation of shoot, for example, the function yields a relation that can only hold between $\mathrm{x}$ and $\mathrm{e}$ if $\mathrm{x}$ is hit in $\mathrm{e}$.

3. Semantic types: Individuals e, propositions t, eventualities s, times i. Variables: $\mathbf{x}_{\mathrm{e}}, \mathrm{x}_{\mathrm{e}}, \mathrm{e}_{\mathrm{s}}$, $\mathrm{e}_{\mathrm{s}}, \mathrm{t}_{\mathrm{i}}, \mathrm{P}_{<\mathrm{st}>}, \mathrm{Q}_{<\mathrm{it}>,}, \mathrm{R}_{<\mathrm{e}<\mathrm{st}>>}$. Stems that can produce 'target state adjectival passives' (Kratzer 2000) would have a state argument in addition to the event argument, and the characterization of the meaning of those verbs would have to include a target state description. I will neglect this issue here for convenience. For reasons of space, I will also not be able to go into the semantics of verbs of creation, even though verbs of creation provide the best illustrations for conative alternations in German. See Zucchi 1999 for what the major issues are and Zimmermann 1995 for a general discussion of verbs with opaque object positions. 
The predicate 'culminate' in the logical-conceptual representations of (4) is a twoplace predicate, and this distinguishes it from Parsons' notion of culmination. For Parsons, culmination is a mere property of events. As pointed out in Zucchi 1999, the problem with Parsons' proposal is that events never culminate per se. A particular cleaning event, for example, might culminate as an event of cleaning my kitchen, but might not reach culmination with respect to cleaning my house ${ }^{4}$. To account for the relativity of culmination, the logical-conceptual predicate 'culminate' in (4) is relativized to the direct object argument. Such an analysis implies a claim about the role of the direct object argument for the culmination condition. Only direct objects participate in defining culmination ${ }^{5}$. This is one way of accounting for Tenny's generalization that only direct internal arguments can 'measure out' the events described by a verb ${ }^{6}$. The proposal is also in the spirit of Ramchand 1997 in that it allows [telic] to flesh out the role the referents of direct objects play in their respective events ${ }^{7}$.

The account of telicity in (4) consists of a lexically determined condition on culmination that interacts with an inflectional head imposing culmination ${ }^{8}$. It

4. Our verb denotations do not satisfy Krifka's Uniqueness of Objects or Uniqueness of Participants, then. Krifka 1989, 1992, 1998.

5. The generalization will eventually have to be qualified in light of the discussion of measure and degree phrases below.

6. Tenny 1987, 1994.

7. In contrast to Ramchand 1997, the present proposal does not require neo-Davidsonian association of the direct object argument. See Kratzer (forthcoming) for discussion of this issue. 8. Terminology is confusing in the area of Aktionsarten and aspect. Streitberg 1891 distinguishes between imperfective (or durative or continuative) and perfective (or resultative) Aktionsart. He argues for two types of perfective verbs: instantaneous and durative perfectives. Streitberg's instantaneous perfectives correspond to achievement verbs, and his durative perfectives correspond to accomplishment verbs in the now common English classification. I will use the pair 'telic'/'atelic' to mark Aktionsart differences, that is differences that have to do with whether or not 
contrasts with the purely algebraic accounts of telicity adopted by many researchers in the field, following Krifka 1989, 1992. Algebraic accounts use properties like quantization to capture semantic properties such as telicity. A property of events is quantized if whenever it is true of an event, it isn't true of any of its proper subevents. One of the properties traditionally used to diagnose telic VPs is incompatibility with durational adverbials. While algebraic accounts have been successful in picking out VPs that are or aren't compatible with durational adverbials, they do not quite give us the notion of telicity we need. Compare 5(a) to its conative alternant $5(\mathrm{~b})$ :

(5) a. Sie hat tagelang Fausthandschuhe gestrickt. She has for days mittens - Acc knit. She knit mittens for days.

b. Sie hat tagelang an Fausthandschuhen gestrickt. She has for days at mittens - Dat knit. 'She was knitting mittens for days.'

Conative alternations have properties similar to the Finnish alternations we looked at earlier. A case alternation correlates with an Aktionsart difference. The crucial observation is that 5(a) implies that there were mittens that she knit. The event culminated in that sense. In contrast, 5(b) does not have that implication. No mittens need to have come into existence. In order to account for the essential properties of the conative alternation, then, we have to be able to talk about whether or not the events described are complete in the sense of satisfying the culmination condition determined by the VP. Incompatibility with durational

culmination is implied. I will reserve the pair 'perfective'/'imperfective' to mark differences brought about by compositional higher aspectual operators. Those differences have to do with what I would like to call 'viewpoint aspect', following Smith 1991. According to the terminology I adopted, 'perfective' and 'imperfective' operators relate event times to the time we are talking about, the reference time. In this sense, they relate to the way events are 'viewed'. See also Filip 2000, who argues at length for drawing this kind of distinction for Slavic. 
adverbials is not a test for telicity when bare plural objects are involved. Both 5(a) and (b) are compatible with a durational phrase. A similar point can be made with respect to another widely used tool for diagnosing telicity: modifiers like in less than three days. Those do seem to pick out telic VPs in the sense we are after, but that only shows that algebraic properties like quantization don't. Neither one of the underlined VPs in 6(a) and (b) expresses a quantized property of events, for example ${ }^{9}$.

(6) a. Sie kann in weniger als drei Tagen wunderschöne She can in less than three days wonderful

Fausthandschuhe stricken. mittens - acc knit She can knit wonderful mittens in less than three days.

b. * Sie kann in weniger als drei Tagen an wunderschönen She can in less than three days at wonderful

Fausthandschuhen stricken. mittens - dat knit

While telicity in the sense needed here can't seem to be defined in terms of properties like quantization, algebraic properties might still be successful in defining culmination ${ }^{10}$. They might give us an operator that can turn atelic verb stems of all kinds into telic ones, thus creating telic predicates, rather than merely selecting them. Algebraic properties related to Krifka's Mapping to Events are promising here. Mapping to Events links the progress of the events a transitive verb describes to the part structure of its direct object referent. We could say, then, that

9. The modal and the position of the object make sure that the indefinite is not 'specific'. Thanks to Roger Schwarzschild for pointing out the need to exclude a specific interpretation. 10. The following attempt to eliminate 'culminate' as a primitive was prompted by comments I received from Roger Schwarzschild rightly questioning the role the notion 'culminate' plays in (4). 
those events culminate when the activity described by the verb has affected all relevant parts of the direct object referent. Here is a more technical way of saying this. Suppose $\mathrm{R}$ is the relation denoted by some transitive verb and $\mathrm{R}$ holds between an individual $\mathrm{x}$ and an event $\mathrm{e}$. The event $\mathrm{e}$ culminates with respect to $\mathrm{x}$ just in case for every part x' of $x$ there is a part e' of e such that $R$ holds between $x$ ' and e'. As emphasized in Schwarzschild 200211, the part structures relevant for measurement are often given by convention and can vary from one context to the next. When it comes to climbing mountains, for example, bands of equal elevation seem to determine the units for the relevant part structure, cutting up the mountain into horizontal slices resembling those you see in pictures illustrating different climate zones on a mountain. It is now legitimate to say that an event of climbing up Mount Monadnock, for example, culminates with respect to Mount Monadnock, if every relevant part of that mountain has been climbed up. Among the relevant parts is the top part, of course, and assuming a sufficiently fine-grained part structure, having climbed up all parts of the mountain means that the top of the mountain has been reached ${ }^{12}$. The mountain, then, literally becomes a measuring tool for the

11. The most extensive linguistic discussion of the flexibility of part-whole structures in a variety of domains is Moltmann 1997.

12. Since there is contextual flexibility with respect to part structures, it is in principle possible for you to climb up all relevant parts of a mountain without reaching the top. You could have a sufficiently big top part, for example. You could climb up that part without climbing it up all the way. The smaller a part, the harder it gets to not climb it up all the way when climbing up that part. The predicted consequences of part structure flexibility are welcome. It's not a contradiction to claim that I climbed Mount Monadnock, but didn't quite make it to the summit. On the approach illustrated in (8), we would attribute this judgment to a relatively coarse part structure. The volatility of part structures matches the volatility of judgments. A pedant can always push for a more fine-grained part structure as in "No, if she didn't reach the summit, she didn't climb Mount Monadnock". Flexibility in part structure only allows a little bit of tolerance with respect to the completion requirement, however, and can't be pushed to the point where Singh's I ate my cake today and will eat the remaining part tomorrow is accepted as non-contradictory in English (Singh 1998). The fact that corresponding perfective Hindi sentences are not contradictory suggests that [telic] 
success of the climb. It provides a suitable part structure, as well as an upper bound for a corresponding scale. If all verbs were like climb, we could drop the culmination conditions in the meaning assignments for individual verbs and let [telic] impose a 'one fit all' culmination condition as in (7):

$$
\begin{array}{ll}
\text { Climb- } & \square \mathrm{x} \square \mathrm{e} \operatorname{climb}-\mathrm{up}(\mathrm{x})(\mathrm{e}) \\
\text { [telic] } & \square \mathrm{R} \square \mathrm{x} \square \mathrm{e}\left[\mathrm{R}(\mathrm{x})(\mathrm{e}) \& \square \mathrm{x}^{\prime}\left[\mathrm{x}^{\prime} \leq \mathrm{x} \quad \square \quad \square \mathrm{e}^{\prime}\left[\mathrm{e}^{\prime} \leq \mathrm{e} \& \mathrm{R}\left(\mathrm{x}^{\prime}\right)\left(\mathrm{e}^{\prime}\right)\right]\right]\right]
\end{array}
$$

If the denotation of [telic] was as in (7) we would be able to derive some good consequences for Finnish. As pointed out in Kiparsky 1998, the Finnish counterparts of English verbs like own or know take accusative direct objects ${ }^{13}$, even though they are compatible with durative adverbials. Interestingly, the denotations of those verbs all satisfy Mapping to Events, hence would automatically satisfy the conditions imposed by [telic] on the present approach. If you own a house, that ownership includes ownership of the parts of the house. If you know your field, that knowledge includes knowledge of its subfields. In contrast, loving your neighbor doesn't include loving his relevant parts. Finnish reflects that difference. Love takes partitive objects, along with hate, admire, and so on.

Not all verb stems that should be able to combine with [telic] readily suggest a nontrivial part structure for the referents of their direct objects, however. A case in question is the denotation I posited for the stem of the verb shoot. If you shoot at a bear, it's not the bear itself, but possible paths leading from your gun to the animal that provide measures for success. You shoot the bear, it seems, just in case you shoot at all parts of some path leading to him. We could now try to adjust the

may not be present in those sentences. Interestingly, perfective sentences follow an ergative case marking pattern in Hindi, and all depends now on the status of objective case in those sentences, a very relevant issue that I cannot pursue further within the limits of this chapter, unfortunately. 13. Except with indefinite bare plural or mass noun objects. See section 3. 
denotation of [telic] by allowing not only the direct object referents themselves, but also possible paths leading to them and other related entities to serve as 'measuring rods' for the success of the events described by the verb. This gives us lexical denotations of the kind illustrated in (8):

$$
\begin{array}{ll}
\text { Climb- } & \square \mathrm{x} \square \mathrm{e} \operatorname{climb}-\mathrm{up}(\mathrm{x})(\mathrm{e}) \\
\text { Shoot- } & \square \mathrm{x} \square \mathrm{e} \text { shoot-at(x)(e) } \\
\text { [telic] } & \square \mathrm{R} \square \mathrm{x} \square \mathrm{e}\left[\mathrm { R } ( \mathrm { x } ) ( \mathrm { e } ) \& \square \mathrm { f } \left[\text { measure(f) \& } \square \mathrm { x } ^ { \prime } \left[\mathrm{x}^{\prime} \leq \mathrm{f}(\mathrm{x}) \square \square \mathrm{e}^{\prime}\left[\mathrm{e}^{\prime} \leq \mathrm{e} \&\right.\right.\right.\right. \\
& \left.\left.\left.\left.\mathrm{R}\left(\mathrm{x}^{\prime}\right)\left(\mathrm{e}^{\prime}\right)\right]\right]\right]\right]
\end{array}
$$

The feature [telic] turns originally atelic stems like climb-or shoot-into telics. The main burden of the analysis is now carried by the assumption that there is some general cognitive mechanism that determines a range of functions that map the referents of certain direct objects into concrete or abstract 'measuring rods' that are associated with those referents in some way or other. We would want to include the identity function as one possibility here, of course, as well as functions mapping individuals into some path leading to them, and hopefully not too many other kinds. A likely constraint is that direct object referents provide upper bounds for the relevant scales. If the assumption of such a general cognitive mechanism could be maintained, the format for lexical representations in (4) could be replaced by the one in (8), which has a more elegant division of labor between verb stem and [telic] and avoids the redundancies implicit in (4).

The approach to telicity exemplified by (8) is very much in the spirit of Hay, Kennedy, and Levin 1999, who emphasize that linguistic and contextual factors interact to create the phenomenon of telicity. I have to add a qualification, though. Hay, Kennedy, and Levin argue that the notion of 'incremental theme' in the sense of Dowty 1991 should be construed as a measure of some property of a verb argument, rather than as that argument itself. With respect to Dowty's mow the lawn, for example, they propose that the true incremental theme is not the lawn 
itself, but its area, a property of the lawn. However, if [telic] is to play the role it plays in (8), we do not want to exclude concrete objects like lawns or apples from being incremental themes. A 'one fit all' notion of culmination can only work along the lines of (8) if we are able to say, for example, that my eating the apple was successful just in case I ate from every part of it. We do not eat abstract properties of apples like their volume, for example. We can agree with Hay, Kennedy, and Levin's claim that incremental themes are scales associated with direct object referents, however, if we are willing to entertain the idea that a mountain with a suitable part structure might be a scale. Why not?

Not all transitive verbs in Finnish alternate between accusative and partitive direct objects. In particular, there are transitive verbs that require accusative objects ${ }^{14}$. Achievement verbs like those corresponding to win or lose are in this group. The stems of those verbs seem to have telic denotations from the very start ${ }^{15}$. Consequently, they do not need [telic] to become telic. [Telic] still needs to be there, however, for direct objects to check their accusative case features. Once present, [telic] imposes a semantic requirement that win and lose have to satisfy like all other stems that combine with [telic]. Take lose as in lose your hat. The VP lose your hat describes instantaneous events, and that means that it describes events that have no proper subevents that are also losing events. When lose your hat combines with [telic], then, and we talk about a single event, the requirement is that your whole hat be lost in that one instantaneous event. A parallel account can be given to win as in win the race. If win the race, too, describes instantaneous events, those events can't be the sum of proper subevents in which parts of the race are won. The whole race must have been won in one instantaneous win. The trivial

14. Exceptions are indefinite bare plural and mass noun objects, of course. See section 3 below.

15. In contrast to simple accomplishment verbs, the Hindi counterparts of win and lose imply completion according to Singh 1998, along with other achievement verbs and complex accomplishment verbs. 
part structure of the events described by achievement verbs, then, forces a trivial part structure for the referents of their direct objects.

Suppose (8) represented the general way accomplishment verbs are built in some language. That language would only have two kinds of eventive verb stems, then: telic ones, which already imply culmination, and atelic ones, which don't. The first class would include the stems for verbs that are traditionally labeled 'achievement verbs'. Crucially, there would be no verb stems that merely characterize a culmination condition without already implying culmination. Culmination conditions for verbs built from atelic stems could be inferred using general cognitive principles, rather than relying on knowledge of lexical meanings as in (4). Any transitive process or activity verb in such a language would be expected to combine with [telic], as long as suitable measures for the success of the events described could be associated with the verb's direct object, often in interaction with contextually provided information. In a language of this kind we would expect to find a large class of transitive verbs that alternate between telic and atelic uses. We would also expect to find a class of verbs that only have telic uses. And verbs like love, admire, hate, enjoy, and so on should be unambiguously atelic. Those verbs describe processes or states that do not affect the referents of their direct objects directly. It is therefore hard to see how those referents could provide bounds for scales measuring the success of the events described.

Are there languages that only have two kinds of eventive verb stems? Finnish might be one. German or English, might be, too. Maybe there is no language that has the kind of accomplishment stems posited in (4). Here is a fact that bears on the issue, at least for English and German. English and German each have a large class of 
transitive verbs that show telic as well as atelic behavior according to the standard tests ${ }^{16}$ :

(9) a. The doctor examined the patient in/for an hour.

b. We cooked the egg in/for five minutes.

c. We milked the cow in/for ten minutes.

d. She cleaned the house in/for two hours.

The list of English verbs that alternate in this way is very long and includes the following, for example:

(10) Read, examine, analyze, barbecue, roast, iron, bathe, massage, wash, comb, brush, fry, polish, explain, confuse, pollute, control, cover, insulate, test, decorate, describe, drain, mop, survey, check ....

Alternating verbs as in (9) are typologically not uncommon. McClure 1995 reports that in Japanese, every activity verb can have a telic interpretation under the right circumstances. The existence of alternations like the ones in (9) is an expected consequence of (8). Turning atelics into telics, possibly with the help of contextual information, would be the normal job of [telic]. However, there is one crucial fact that we wouldn't expect under the analysis illustrated in (8). Why is it that in English or German we still find accusative objects with the atelic alternants in (9) or (10)? I will come back to this important difference between German and English on the one hand, and Finnish on the other, towards the end of this chapter. In the

16. See Levin 2000 for more relevant examples and discussion, and Hay, Kennedy, and Levin 1999 for a detailed examination of telic/atelic alternations with so-called "degree achievement" verbs. The examples in (9) do not have bare plural objects, hence the objections to the standard tests for telicity I raised earlier do not apply here. 
meantime, let us tentatively assume that the account illustrated in (8) is on the right track and explore what the consequences are.

The denotations for the stems for accomplishment verbs assumed here share with both Parsons' and Zucchi's denotations that they describe events that might or might not have culminated. It is that property that generates systematic telic/atelic alternations. Zucchi 1999 considers the possibility that the atelic portions of the denotations of accomplishment stems might not be there from the very start, as assumed here, but might be 'generated' from telic denotations by the same operation that derives progressives in English. This proposal cannot easily accommodate the fact that the atelic meanings we find in conative alternations are not always exactly the same as the corresponding progressive meanings. Here are some examples illustrating subtle differences. Imagine a herd of buffaloes that is running towards you. You fire a shot to make them turn around and run in the opposite direction. In such a situation, 11(a), which has a progressive verb form, is false, but 11(b), which has the atelic alternant of the shoot/shoot at conative alternation, is true.

(11) a. I was shooting the buffaloes.

b. I shot at the buffaloes.

The meanings of $12(a)$ and (b) also differ in a subtle way:

(12) a. Nina was knitting a mitten.

b. Nina hat an einem Handschuh gestrickt. Nina has at a-dative mitten knit.

Suppose Nina was in the process of knitting an incomplete mitten as a prop for a movie. Since an incomplete mitten was needed for that particular movie, the mitten never meant to be completed. Another example was given to me by Roger Schwarzschild (p.c.), who thought about a Mr. Caliendo, who accidentally assigned 
his math class a homework problem that couldn't be solved. To describe Jack's attempts at the homework, 13(a) is more appropriate than 13(b):

(13) a. Jack worked on a solution to the homework problem.

b. Jack was solving the homework problem.

13(b) is false because the progressive claims that there are accessible worlds where the homework problem is solved. 13(a), on the other hand, can be true even though the events described can't possibly culminate ${ }^{17}$. I conclude that we have to distinguish between the atelic denotations found in conative alternations and those produced by operators like the progressive operator in English. The atelic meaning components of accomplishment verb stems, then, might very well be basic.

To summarize, I have proposed that the telicity of accomplishment verbs might be produced by atelic verb stems in interaction with an inflectional head that imposes culmination, possibly in interaction with contextually provided information. I argued that telicity as a property of predicates cannot be characterized via algebraic properties like quantization, as proposed by Manfred Krifka and much recent work, but considered the possibility that the notion of culmination itself might be characterized algebraically using a property closely related to Krifka's Mapping to Events. The strategy was to think of [telic] as an operator that can create telic predicates in interaction with the lexical meanings of verb stems, rather than merely selecting predicates that are already telic. By granting the direct object argument an essential role in defining culmination, it became possible to account for Tenny's generalization that direct object arguments measure out the events a verb describes, and to do justice to Ramchand's insight that [telic] affects the very way the referents of direct objects relate to their events. I also considered and

17. Like stricken an ('knit at') in 12(b), work on in 13(a) is a verb of creation, hence has an opaque object position. Working on a solution does not imply that there is a solution. See note 3. 
rejected Zucchi's proposal to use existing theories of the progressive to link the telic and atelic components in the denotations of stems for accomplishment verbs.

Turning to the syntax of telicity, Figure 1 below gives an example of a structure built from the transitive verb stem climb, the inflectional head [telic], and the DP The Matterhorn ${ }^{18}$.

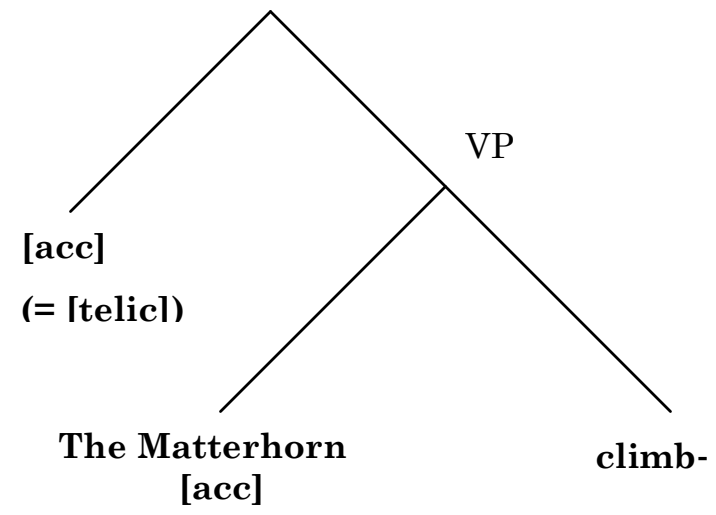

\section{Figure 1}

The DP The Matterhorn has the uninterpretable feature [acc], which forces it to enter an agreement relation with the verbal inflectional feature [acc] (= [telic]). In this particular configuration, establishment of an agreement relation between the DP The Matterhorn and [telic] must be followed by displacement of that DP. If The Matterhorn was interpreted within its VP, the VP [telic] operates over would denote a mere property of events rather than the required relation between individuals and events.

What is it that could force the DP The Matterhorn to leave its VP? If it stayed put, the semantic interpretation procedure would crash due to a semantic type

18. I am neglecting at this point the possibility that verbs might enter the syntactic derivation fully inflected. If they are, those pieces of inflection would be meaningless and would have to be matched by possibly meaningful inflectional features heading their own projections within the hierarchy of inflectional heads. The essence of my account would not be affected by that possibility. 
mismatch. But how should a DP sitting in the wrong place know about that? Suppose, then, that [telic] possesses a feature that allows it to attract a DP. Following Chomsky 1995, Collins 1997 and later work within Minimalism, such a feature might be called an "EPP" or "D"-feature. What are EPP or D-features? I propose to identify them with indices, with the special provision that indices are now taken to be features, too, rather than some special breed of syntactic objects. We have index features, then. An immediate consequence of this proposal is that in order to enter an agreement relation with each other, [telic] (= verbal [acc]) and the DP The Matterhorn have to be co-indexed. In drawing this conclusion, I am assuming that if there are such things as index features, then DPs would be the kind of category that can have them. Consequently, agreement between The Matterhorn and verbal [acc] $]_{1}$ has to include agreement with respect to the index 1. Instead of the structure in figure 1 , we would now start out with the one in figure 2 :

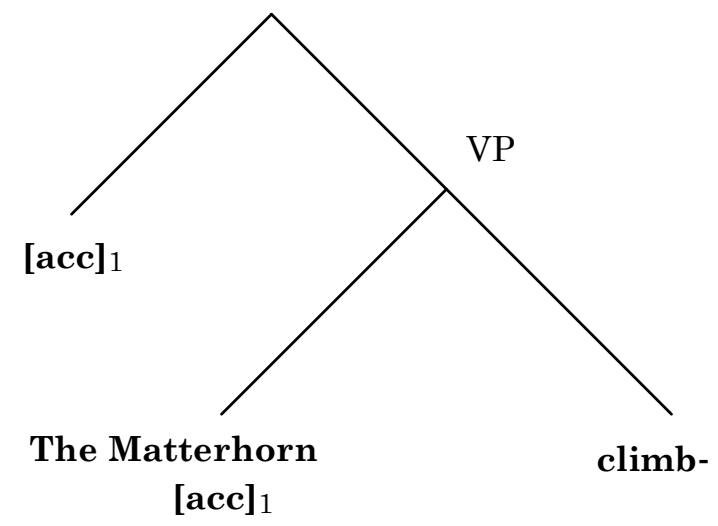

\section{Figure 2}

If EPP or D-features are identified with indices, we expect that identification to literally derive the fact that such features can force displacement ${ }^{19}$. To see that it does, we have to think about the interpretation of indices. Indices are never PFlegible. Let us assume that they have to be LF-legible. Following Heim and Kratzer

19. As usual with identifications, we do not expect index features to cover exactly the range of functions that EPP or D-features are assumed to have in the literature. They cover a large chunk of cases, though. 
1998, let us suppose furthermore that indices can be interpreted at LF as either binder indices ( $\square$-operators) or variables, depending on their syntactic position. In the structure of figure 2, the index on [telic] can be parsed as a separate head and can then be interpreted as a binder index ( $\square$-operator). What about the index of the DP The Matterhorn? If indices are features, the index of a DP has to be projected from the index of the $\mathrm{D}$ that heads it via the usual process of feature percolation. Indices can no longer be assigned to whole DPs by some special indexing mechanism. They must originate with lexical items - determiners in our case. But indices that are bundled with determiners are not interpretable, they are not LFlegible, that is. It seems, then, that this situation forces displacement of DPs. The DP moves, leaving a part of its determiner (the index and possibly other features) behind. If we assume a copy theory of movement, displacement has the effect that the lexical and feature content of a DP is distributed over two positions. In a first step, the DP is copied into the higher position. In a second step, parts of the original and/or the copy are deleted. In our case, LF-legibility for the index feature of the DP The Matterhorn forces that feature to be left behind in the base position, where it can be interpreted as a 'trace'. Trace theory, then, falls out from the copy theory of movement. We have:

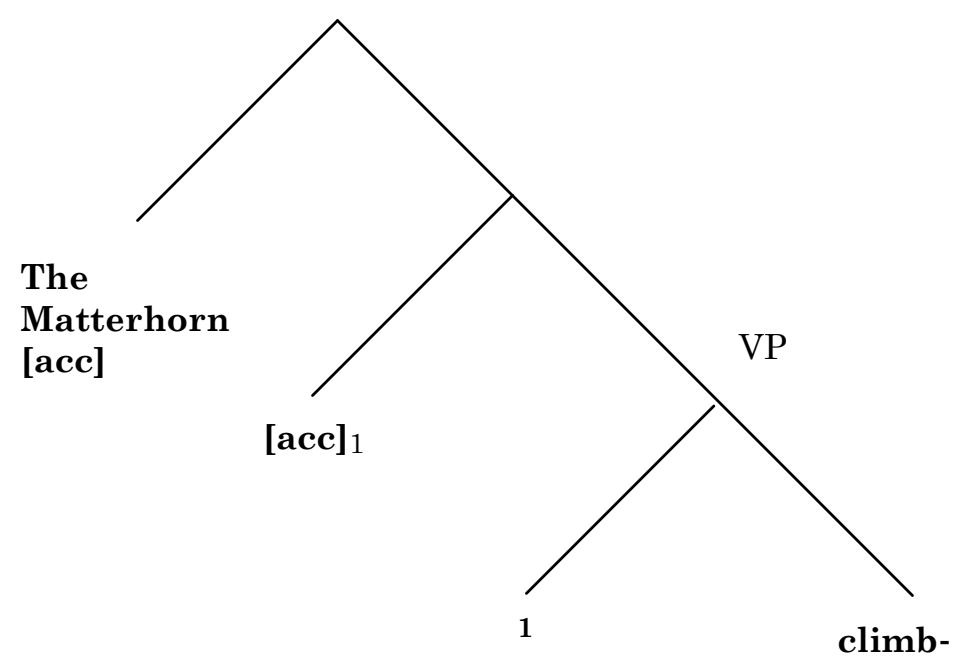

Figure 3 
After deletion of the uninterpretable nominal [acc] feature via agreement, the result is the structure in figure 4 , which can be interpreted with standard techniques.

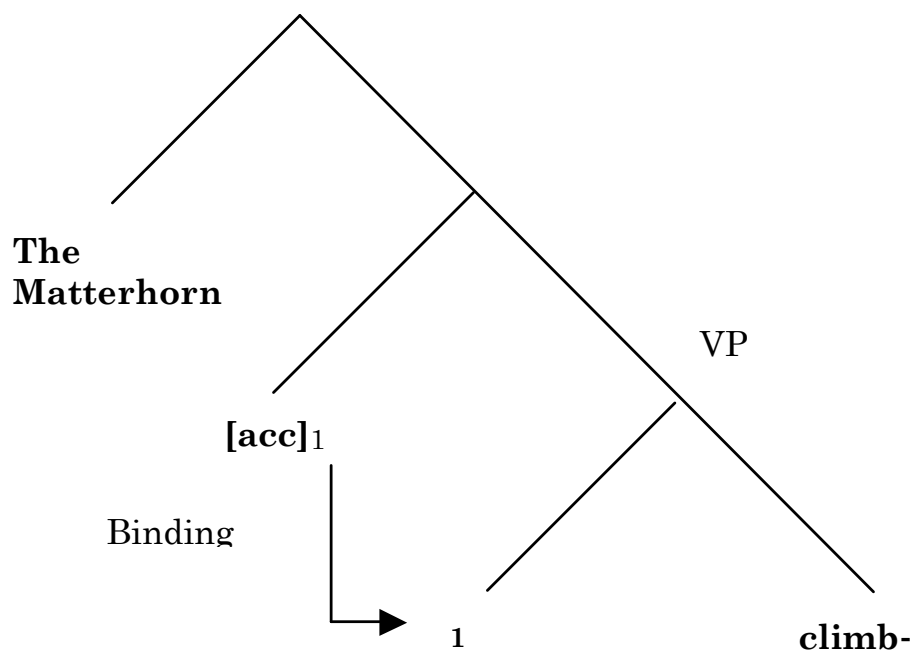

\section{Figure 4}

Being a binder index, the index of [acc] in figure 4 binds the index left in the base position of the direct object. As desired, the structure in figure 4 is a constituent that denotes a relation between individuals and events. In our example, that relation is identical to the denotation of $\operatorname{climb}$.

We have now seen how the semantic requirement that [telic] operate over a constituent denoting a relation between individuals and events can be syntactically encoded by the presence of an index feature that comes with [telic]. This is one way of saying that [telic] has an EPP feature or a D-feature. Presence of an index feature on [telic] forces the presence of a matching index feature on any DP that wants to agree with it. For that last feature to be LF-legible, however, the DP that carries it has to split in two, leaving the index feature (and possibly other features of its determiner) behind. 
After going through this derivation of the LF-representation in figure 4, we might wonder whether optimal design considerations might not favor a simpler derivation that directly starts out with the structure in figure 3 . In figure 3 , the object position of the verb is saturated with an index feature and possibly other agreement features. Technically, what we have done, then, is fill the verb's argument position with what looks just like object agreement morphology. This is the minimal way of realizing an argument, hence the minimal way of satisfying the thematic requirements of a verb ${ }^{20}$. The full DP The Matterhorn could now be placed directly into the specifier position of verbal [acc] (=[telic]). No copy or deletion operations would be necessary. I will have to leave serious exploration of this possibility for future work.

In this section, we have seen evidence that the syntactic construction of telicity is not only desirable, but - even more importantly - it is also feasible, both syntactically and semantically. An uninterpretable nominal feature [acc] can be checked (hence 'licensed') by a matching interpretable verbal feature that requires the events described to culminate with respect to the direct object referent. We are now ready to return to the alternations in Finnish that were the main motivation for the analysis presented in this section. I will pursue the consequences of my analysis for German (and to a limited extent for English) in sections 4 and 5.

\section{Reanalyzing Finnish}

When taking a second look at the Finnish alternations, I suggest we separate out the NP-related cases of partititive case, which means giving up Kiparsky's unified account of partitive direct objects. There are a number of reasons for such a move.

20. I am assuming that the thematic requirements of lexical elements have to be satisfied within their projections, and that, consequently, the lexical requirements of verbs have to be satisfied within their VPs. Otherwise, verbs and [telic] could be combined before processing direct objects, of course. 
In Finnish, bare indefinite plural and mass objects always have partitive case, regardless of the verb. Kiparsky subsumed those occurrences of partitive under the semantic property of unboundedness of the relevant VP. However, Kiparsky's unification is not without problems. Many languages, including earlier stages of Finnish, only have the NP-related partitive (Kiparsky 1998). Moreover, partitive case in Finnish is generally used for the objects of prepositions (Vainikka 1989) and in some other environments. Finally, Finnish partitive shows up DP-internally, as in 3(b) from above:

$$
\begin{aligned}
& \text { b. Ammu - i - n kaksi } \quad \text { karhu-a. } \\
& \text { Shoot - past - 1sg two-acc } \quad \text { bear-part } \\
& \text { I shot two bears. } \\
& \text { I shot the two bears. }
\end{aligned}
$$

Not all occurrences of partitive can be straightforwardly subsumed under the VPunboundedness account, then. Since partitive occurs DP-internally as in 3(b), it is plausible to assume that NP-related partitive is in fact an instance of a DP-internal partitive. There would then be an unpronounced $\mathrm{D}$ bearing either partitive or accusative case, you can't see which. DPs with unpronounced D's are known to be restricted to governed positions in Romance. Finnish NP-related partitive are confined to VP-internal positions according to Kiparsky 1998, a generalization that is likely to be covered by whatever explanation is given to the distribution of Romance bare nouns. The presence of an unpronounced $\mathrm{D}$ would also explain the otherwise odd fact that in (14), an accusative DP seems to be conjoined with a partitive one:
Ost-i-n
lehden ja kirjo-j-a.
Buy-past-1sg newspaper-sg acc and book-pl-part 'I bought the/a newspaper and books.'
Kiparsky 1998, 275. 
After discarding the NP-related partitive, the link between case and Aktionsart emerges more clearly: Roughly, telic verbs take accusative objects. Atelic verbs take partitive objects:

(15) $\underline{\text { Telic }}$

Ostaa ('buy'), ottaa ('take'), pudottaa ('drop'), suorittaa ('carry out'), kadottaa, menettää, hukata ('lose' (possession) ), hävitä ('lose' (a game or fight) ), löytä̈̈ ('find'), hyväksyä ('accept'), panna, asettaa ('put'), tappaa ('kill'), antaa, lahjoittaa ('give'), kaataa ('fell') ... (Kiparsky 1998, 281.)

$\underline{\text { Atelic }}$

Halveksia ('despise'), ihailla ('admire'), kadehtia ('envy'), rakastaa ('love'), matkia ('imitate'), ravistaa ('shake'), keinuttaa ('rock'), koskettaa ('touch'), hieroa ('massage'),....( Kiparsky 1998, 281).

Many Finnish transitive verbs can have accusative or partitive direct objects, though, with a slight change in meaning. The alternation between 3(a) and (b) from above is representative of this phenomenon.

a. Ammu-i-n kah-ta karhu - a. Partitive shoot - past - 1sg two-part bear - part. I shot at two bears.

I shot at the two bears.

b. Ammu - i-n kaksi karhu-a. Accusative shoot - past - 1sg two-acc. bear - part I shot two bears.

I shot the two bears.

Cases like (3) were the main motivation for the denotations of stems for accomplishment verbs I proposed earlier. Apart from alternations that look like 
typical conative alternations, we also find resultative alternations as in (16), and the use of partitive to induce an ongoing event interpretation, as in (17). ${ }^{21}$

a. Jussi maalas-i talo-n (punaise-ksi).

Jussi-Nom paint-Pst(3Sg) house-Acc (red-Transl)

'Jussi painted the (a) [whole] house (red).'

b. Jussi maalas-i talo-a (punaise-ksi).

Jussi-Nom paint-Pst(3Sg) house-Part (red-Transl)

'Jussi was painting the (a) house (red).'

(17) a. Tapo-i-n juuri karhua.

Kill-Pst1Sg just bear-Part

I was just killing the bear.

b. Matti ost-i (juuri) auto-a, (kun...)

Matti buy-Pst3Sg (just) car-SgPart, (when....)

Matti was (just) buying a car, (when....)'

The alternations in (16) and (17) are expected under the current perspective. They are no longer cases of 'coercion'. When the direct object of a verb is an indefinite 'bare' plural or mass NP, we can't tell whether it has accusative or partitive case, assuming that there is an unpronounced determiner. In (18), for example, that determiner would have accusative case for reading (a), and partitive case for readings (b) and (c):

(18) Hän kirjoitt-i kirje-i-tä.

$\mathrm{He} /$ she write-past-3sg letter-pl-Part

a. He wrote letters (...and left)

b. He was writing letters (...when I came)

c. He was writing the letters (...when I came)

Kiparsky 1998, 272.

21. The examples are from Kiparsky 1998. (16) is from p. 292 and (17) from p. 289. 
Vainikka 1989 characterizes accusative in Finnish as a case that "has a very narrow distribution"22. It only occurs with telic verbs. For Vainikka, accusative case "is literally assigned by a specific head (or feature)."23 This limited distribution is explained if [acc] on nouns is in fact the uninterpretable version of [telic]. While a semantic interpretation for DP-internal partitive in terms of 'part of' is conceivable, it's hard to see how all occurrences of partitive could be given a common interpretation. Vainikka thus considers partitive case a structural 'default' case. Within the current framework, this would mean that Finnish [part] is uninterpretable. Like [acc], [part] would be both a verbal and a nominal inflectional feature participating in agreement relations between nouns and verbs.

To prevent partitive from taking over as the only objective case, a principle along the lines of (19) would have to be posited:

Maximize Interpretability.

Suppose (19) is interpreted in such a way that it forces speakers of Finnish to pick accusative case for the direct object, unless the resulting interpretation would clash with what they intend to say. Partitive should now be used whenever a commitment to culmination is to be avoided. With verb stems that already imply culmination, accusative should be obligatory. There is no way of avoiding a commitment to culmination with those verbs. According to Kiparsky, an achievement verb like win cannot take partitive direct objects ${ }^{24}$ :

\footnotetext{
22 . p. 147.

23 . p. 156.

24. Maximize Interpretability is satisfied when the stems of achievement verbs combine with [telic]. It comes at the price of semantic redundancy, however, as Roger Schwarzschild (p.c.) points out. Semantic redundancy is the signature of agreement phenomena, so there must be a benefit to
} 
If there is a principle like (19), it should not be a principle that merely holds for Finnish. In the best of all possible worlds, it would be a universal principle. Suitably interpreted, we expect it to play a role in language acquisition. Granting (19) a role in acquisition generates predictions about languages that, unlike Finnish, do not have two structural objective cases. In the remainder of this paper I will investigate some of those predictions for German, keeping in mind the English situation as well.

\section{German is not Russian}

A child learning German will only encounter a single structural objective case. His first task is to identify the case he finds. Suppose the child is equipped with a universal set of possible case meanings: a few linked to particular thematic relations like beneficiary, possessor, and what have you, one related to telicity, and possibly some others. Direct objects do not have a common thematic role in German ${ }^{25}$. The nominal accusative feature should be uninterpretable, then. Since uninterpretable features must be checked, a matching verbal feature is required. This feature could in principle be interpretable or uninterpretable. What role might Maximize Interpretability play in guiding a child towards one or the other option? Suppose Maximize Interpretability forces a child to pick [telic], rather than uninterpretable verbal [acc], unless he finds evidence that is incompatible with such

redundancy. In our case, the gain is that telicity is now very consistently and visibly associated with accusative in Finnish, which should help children pick up the connection.

25. See Kratzer (forthcoming) for arguments against a thematic role 'theme'. 
a choice, assuming general principles of syntactic organization he brings to the task. To see what relevant counterevidence might look like, let's switch to Russian.

A Russian child will find out before long that the telicity of Russian verbs is predictably linked to a set of prefixes ${ }^{26}$. Verbs without such prefixes are typically atelic. He will also notice that the difference in telicity does not affect the case choice for direct objects. Accusative case appears with objects of telic and atelic verbs alike. Moreover, as in German, nominal accusative does not seem to be linked to any particular thematic role in Russian, hence should be uninterpretable. Suppose now that general principles of grammar construction tell the child to look for a verbal feature that can check instances of nominal [acc], preferably in a uniform way. Suppose he picks [telic]. That feature is compatible with prefixed transitive verbs in Russian, just as it is compatible with Finnish achievement verbs. It is redundant, but doesn't create trouble. When combined with prefixless transitive verbs, however, [telic] would immediately render them telic, contrary to what the child observes. He should therefore pick uninterpretable verbal [acc] to check the uninterpretable case feature of direct objects. We will see shortly that, in spite of superficial similarities between Russian and German verbs, the German child finds himself in a very different situation. As a result he will be pushed to choose the Finnish option for checking the case of direct objects.

At first glance, German verbs do not look too different from their Russian counterparts. As in Russian, simplex verbs often have atelic uses and usually come

26. That telicity is predictably linked to a class of prefixes in Slavic does not imply that those prefixes have a compositional (that is, predictable) semantics. See Filip 2000. If telicity is linked to prefixes in Russian, verb stems with those prefixes do not merely determine a culmination condition; they imply culmination. Russian verbs with those prefixes are then expected to behave like German achievement verbs in tests like the weiter test discussed below. 
with a large number of different prefixes. The prefixes often render the verb transitive and telic. Take schreiben ('write').
a. Das Blatt beschreiben
The page be-write
'Cover the page with writing'
b. Die Tinte verschreiben
The ink ver-write
'Use up the ink by writing'
c. Die Eltern anschreiben
The parents an-write
'Write to the parents'
d. Den Aufsatz abschreiben
The article $\underline{a b}$-write
'Copy the article'
e. Die Abkürzungen ausschreiben
The abbreviations out-write
'Write out the abbreviations'

The superficial impression that German and Russian are alike in the way they use prefixation to mark telicity is elusive, however. The very same prefixes we see in (20) also appear with atelic verbs:

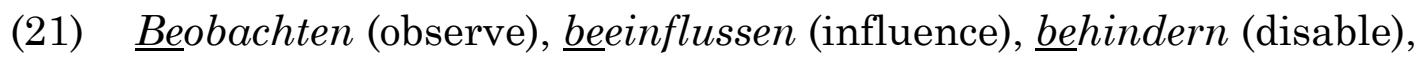
vernachlässigen (neglect), verschonen (spare), verneinen (deny), anbeten (adore), anschreien (yell at), anlocken (attract), abschrecken (deter), sich abquälen (to struggle (with something)), abschweifen (digress), aushalten (endure), sich ausdehnen (expand), aushängen (be posted), .....

The verbs in (21) are no lonely exceptions. Even though there are some German prefixes that are linked to telicity, there is no strong correlation between telicity and verb prefixation once we look at the class of German verbs as a whole. In 
contrast to his Russian cousin, then, a German child does not find systematic overt carriers of telicity in the data he hears. So far so good, but does this difference help us with our search for a verbal head that could check nominal [acc]? Not yet. Suppose the German child picks [telic]. We would then seem to predict that all transitive verbs should end up telic in German, and this prediction looks as wrong for German as it was for Russian.

There is another difference between Russian and German, however, that we have to pay attention to when thinking about the kind of data that a German child is likely to encounter. As illustrated by 22(c), Russian has a compositional suffix (yv)aj, which can derive 'in progress' readings for telic verbs ${ }^{27}$.
a. pis-a-t'
No culmination implication
to write
b. pere-pis-a-t'
Culmination implication
to write over, copy
c. pere-pis-yva-t'
to write over, copy
'In progress' interpretation

Smith 1991, 299.

\footnotetext{
27. Smith 1991, Filip 2000. When talking about Slavic, terminology is particularly difficult. For consistency with the terminology of this paper, I am using the 'telic'/'atelic' pair for the distinction that is marked in Russian by the presence versus absence of the relevant class of prefixes. I'll label the compositional higher aspectual operator $(y v) a j$ an 'imperfective operator'. Implicit in this terminology is the claim that the presence versus absence of the relevant prefixes affects the culmination implication, whereas the presence or absence of the higher imperfective operator affects the relation between event time and reference time, hence viewpoint aspect in the sense of Smith 1991. Unfortunately, this assessment of the Russian facts doesn't seem to be entirely compatible with the discussion of Russian in Smith 1991. I believe that the apparent conflict might be resolved, however, once we look closer at the connection between the presence or absence of a culmination implication and the way event times are related to reference times. I will not be able to pursue this issue here.
} 
In 22(c), the imperfective operator carried by the suffix ( $y v)$ aj could 'neutralize' the culmination implication of a predicate with a telic prefix when it takes scope over it. When we claim that Bartelby is copying a legal brief, for example, we say that there will be a complete copy at some point - not necessarily in the actual world, but at least in a range of reasonably close possible worlds. Filip 2000 argues that the Russian imperfective suffix $(y v) a j$ is a piece of inflectional morphology, whereas the prefixes linked to telicity are derivational. This automatically places the imperfective operator in a higher position. Higher imperfective operators, then, can take telic predicates and map them into predicates that closely mimic the behavior of atelic ones.

Imagine now a language with the following properties: In contrast to Russian, it doesn't have any systematic overt markers of telicity. Like Russian, it has a higher imperfective operator, but unlike its Russian counterpart, that operator is nonovert. A child who is exposed to such a language should be able to pick [telic], hence interpretable verbal [acc] to check the nominal [acc] feature of direct objects without encountering obviously conflicting evidence. The fact that not all verbs behave like telics is no longer a problem. Since the child has an unpronounced higher imperfective operator in his tool kit, he merely has to posit such an operator to instantly undo the effect of a lower [telic], and thus achieve a close match with the facts he observes. I want to argue that German might very well be a language of this kind.

We have already seen that, as a class, German verbs are not overtly marked for telicity in any systematic way. Our next task is to present evidence that German does in fact have an unpronounced higher imperfective operator. It is not too hard to find such evidence. First, look at 23(a) to (c): 
23 (a) Er soll morgen einen Berg besteigen.

He should tomorrow a mountain climb

He is supposed to climb a mountain tomorrow.

(b) Sie soll heute Handschuhe stricken.

She should today mittens knit

She is supposed to knit mittens today.

(c) $\mathrm{Du}$ sollst heute Abend einen Hummer verspeisen.

You should today evening a lobster consume.

You are supposed to consume a lobster tonight.

The verbs in (23) are typical accomplishment verbs. Copying a technique from Streitberg 1891, I embedded those verbs under a root modal. This makes it possible to avoid the possible impact of higher inflectional operators that might obscure the properties of the verbs and verbal [acc]. Each verb is also accompanied by a temporal adverbial that gives us a reference time. The embedded infinitival clauses in (23) all imply culmination of the activities described by the verb during the time picked out by the temporal adverbial. The man in 23(a) doesn't do what he is supposed to do if he doesn't get anywhere near the top of a mountain tomorrow. The woman in 23(b) doesn't do her duty if, by the end of the day, there aren't any mittens she has knit28, and if you want to obey 23(c), you can't save half of your lobster for lunch tomorrow. The verbs in (23), then, cannot get an ongoing event interpretation with respect to the respective reference times.

28. In contrast to Finnish, there is a culmination implication here, even though the direct object is a bare plural. This is expected, since even if bare plurals have empty determiners in German, too, those determiners would have to carry accusative in our example. In Finnish, on the other hand, that determiner could carry partitive or accusative, hence the difference with respect to the culmination requirement. 
The verbs in (23) are part of bare infinitival complements, hence do not project a full hierarchy of inflectional heads. As soon as we examine finite clauses, we can detect the possible presence of a non-overt imperfective operator. Here is an illustration:

(24) Bi-lingual cell phone conversation

You: What are you doing (right now)?

I: Ich besteige (gerade) den Mount Monadnock. I climb (right now) the Mount Monadnock. I am climbing Mount Monadnock (right now).

In (24), the reference time for my utterance is the time of your question. What I am saying in my reply to you is that I am climbing Mount Monadnock, that is, an event of climbing Mount Monadnock by me is in progress at the reference time. The event described by the verb in (24), then, is allowed to be in progress at the reference time.

To have a concrete proposal, a possible denotation for the German non-overt imperfective aspect operator would look as follows ${ }^{29}$ :

$$
\square \mathrm{P} \square \mathrm{t} \square \mathrm{e}[\mathrm{P}(\mathrm{e}) \& \mathrm{t} \square \square(\mathrm{e})] \quad \text { Imperfective (Viewpoint) Aspect }
$$

Here is the effect of (25) on my reply in (24). The operator in (25) creates a property that is true of any time $t$ just in case $t$ is properly contained in the time of a successful climb of Mount Monadnock by me. This property is then applied to the reference time for (24), which is thereby required to be a proper part of my climb. As a result, my climb is represented as an ongoing event.

\footnotetext{
29. The denotation (25) is modeled after Bennett and Partee 1978. The variable ' $t$ ' ranges over intervals of times, and $\square$ is a trace function assigning to events in its domain their running time.
} 
According to (25), the imperfective operator shouldn't successfully combine with achievement verbs that describe instantaneous events. There is no way for those events to be in progress. By the time you talk about them, they are already a matter of the past. This seems to explain the anomaly of (26):

(26) Sie können jetzt nicht mit Goethe sprechen. \# Er stirbt. You can now not with Goethe talk. He dies. 'You can't talk to Goethe right now. He is dying.'

(25) correctly predicts that speakers of German are still committed to culmination when using non-overt imperfective operators with accomplishment verbs. The crucial point is that while culmination at some time is implied in (24), culmination doesn't have to occur during the reference time. To see this more clearly, we have to examine past tense cases. You will not call me a liar if, in spite of good intentions, I did not manage to reach the summit of Mount Monadnock after having said what (24) reports. Somehow, such cases never go to trial. Consider the following example, then:

a. Wieland saß damals (gerade) im Gasthaus und verspeiste Wieland sat then (at the moment) in-the pub and consumed einen Hummer. a lobster. 'Wieland was sitting in the pub then and was consuming a lobster.'

b. \# Er hätte bestimmt mehr als nur ein paar Bissen gegessen, wenn ihm He had certainly more than only a few bites eaten if him ein übereifriger Kellner nicht den Teller weggenommen hätte. a over-zealous waiter not the plate away taken had.

'He would certainly have eaten more than a few bites if an overzealous waiter hadn't taken his plate away.'

The (a) sentence zooms in on a particular contextually salient past situation:

Wieland is sitting in a pub, consuming a lobster. Wieland's action is still in progress 
at the time we are looking at, which can be emphasized by the use of gerade, which forces the presence of the imperfective operator. The (b) sentence fills the reader in on what happened in the end. The lobster wasn't consumed. As a continuation of the (a) sentence, the (b) sentence sounds slightly odd and seems to be not quite in line with what was said before. Knowing what happened, the writer should have used a phrase like 'wanted to consume a lobster'. The implicit imperfective operator that seems to be available in German, then, is different from the English progressive operator, which is a modal operator, allowing the events described to develop and culminate in merely possible worlds (Dowty 1979). It is conceivable that the overtness of the English imperfective operator allows it to include a modal component.

I conclude that there is a non-overt imperfective operator in German. We have learned moreover that that operator must be located above the verbal [acc] head, since, as shown by the embedded infinitives in (23), accomplishment verbs can project verbal [acc] without allowing an ongoing event interpretation. Once a full hierarchy of inflectional heads is projected, an accomplishment verb can always get an ongoing event interpretation in German. German, then, is a language that has an unpronounced imperfective operator that is located above verbal [acc] (= [telic]). Given that it is also a language where, as a class, verbs are not overtly and consistently marked for telicity, a German child is expected to pick [telic], rather than the uninterpretable version of verbal [acc]. Maximize Interpretability would force that choice since it would not conflict with the evidence the child encounters. Non-overt higher imperfect operators operating over [telic] could instantly create predicates that closely mimic the properties of initially atelic VPs. The following section will argue that the picture I painted in this section is not just a possibility. There is direct evidence that verbal [acc] is in fact interpretable in German, hence identical to [telic]. As in Finnish, then, the telicity of German accomplishment verbs is syntactically constructed with the help of unpronounced [telic]. The 
connection between telicity and accusative is as tight in German as it is in Finnish. It's not as visible, though.

\section{German as Finnish without partitive}

A major prediction of the claim that the telicity of German accomplishment verbs is syntactically constructed with the help of unpronounced [telic] is that the culmination requirement enforced by [telic] should be absent if we manage to catch an accomplishment stem below the point where [telic] can appear. Suppose [telic] is an inflectional head right above VP. A good way of testing the hypothesis that German accomplishment verbs are not telic from the start would be to examine compositional verbal compounds that involve V's that haven't been able to project beyond VP. Compounds with the prefix weiter seem to provide the right test cases. They attach to stems that do not yet have whatever it takes to license an accusative direct object. This is shown by the existence of nominalizations like das langsame Weiterbesteigen des Berges ('the slow on-climbing of the mountain'). In these nominalizations, the direct object of the verb besteigen ('climb') can only have genitive case, indicating that whatever verbal inflectional head licenses (and forces) accusative case for direct objects is not yet available when weiter enters the derivation. Consider now the following examples:

a. Wir konnten den Berg weiterbesteigen. We could the mountain on-climb. 'We could continue to climb up the mountain.'

b. Wir konnten die Strasse weiterüberqueren. We could the street on-cross. 'We could continue to cross over the street.'

c. Wir konnten das Geschenk weiterauspacken. We could the gift on-unwrap. 'We could continue to unwrap the gift.'

d. Hans konnte die Suppe weiteressen. Hans could the soup on-eat. 'Hans could continue to eat the soup.' 
The effect of the prefix weiter- is to state that the activity described by the verb it operates over continued. The VP die Suppe weiteressen, for example, describes eating events that are continuations of earlier non-culminating eating events, that is, events in which the soup was not yet consumed. The embedded verbs in (a) to (d) are all typical accomplishment verbs. They all test unambiguously positive in the traditional telicity tests ${ }^{30}$.
a. \# Wir haben den Berg tagelang bestiegen.
We have the mountain for days climbed.
'We climbed the mountain for days.'
b. \# Wir haben die Strasse stundenlang überquert. We have the street for hours crossed. 'We crossed the street for hours.'
c. \# Wir haben das Geschenk stundenlang ausgepackt. We have the gift for hours unwrapped. 'We unwrapped the gift for hours.'
d. \# Hans hat die Suppe stundenlang gegessen. Hans has the soup for hours eaten. 'Hans ate the soup for hours.'

In 29(a) to (d), the presence of a durational adverb produces an interpretation where repeated culminated actions are being described. In the case of 28(d) in particular, the actions thus described may be a bit unusual.

If the culmination condition was already imposed at the point where weiter enters the derivation, it's hard to see why, say, den Berg weiterbesteigen means 'to continue to climb up the mountain'. The culmination requirement, then, is not there in those

\footnotetext{
30. Since the direct objects are definite, the traditional telicity tests are reliable for picking out telicity.
} 
cases. Its absence can't be explained by the presence of infinitival morphology, since infinitival morphology all by itself doesn't affect the culmination requirement as shown by 23(a) to (c) from above ${ }^{31}$. If the stems accomplishment verbs are built from only imply culmination after [telic] has been attached, the facts in (28) are as they should be. In compounds with weiter, typical accomplishment verbs behave exactly like activity or process verbs:

(30) a. Du kannst den Parkplatz weiterbewachen. You can the parking area on-guard. 'You can continue to guard the parking area.'

b. Du kannst mich weiteranschreien.

You can me on-at-yell 'You can continue to yell at me.'

On the other hand, achievement verbs can't combine with weiter, as illustrated in (31) ${ }^{32}$. They yield a deviant interpretation when weiter is attached:

$$
\begin{aligned}
& \text { a. * Wir müssen die Suppe weiteraufessen. } \\
& \text { We must the soup on-up-eat. } \\
& \text { 'We must continue to eat up the soup'. }
\end{aligned}
$$

31. Once a culmination requirement has been imposed, modalization seems to be needed to divert its impact on claims about the actual world. The to in English infinitives has a modal component (as in the man to fix the sink), which seems to make it possible for he continued to climb Mount Monadnock to produce the same kinds of meanings as prefixation of weiter to bare verb stems. English progressive -ing seems to exploit the same technique.

32. There is also an adverb weiterhin, which is acceptable with achievement verbs, but will then yield an iterative interpretation, as in John will continue to wake up at 5 in the morning. The events that are being iterated in this case are the culminated ones. According to the present account, weiterhin would be expected to occupy a higher position in phrase structure, so that it can affect verbs after [telic] has been attached. The usual positional tests show that weiterhin does indeed occupy a higher position than weiter. 
b. * Wir müssen das Buch weiterauslesen.

We must the book on-finish-read

'We must continue to finish reading the book.'

c. * Wir müssen das Spiel weitergewinnen.

We must the game on-win

'We must continue to win the game'

If achievement verbs are built from stems that already imply culmination, it's expected that they shouldn't be able to combine with weiter. You cannot continue activities that are already completed.

We have now seen some evidence confirming that German accomplishment verbs do not start out as telic. They are born as atelics. In contrast to achievement verbs, their telicity is syntactically constructed. The weiter+verb compounds we encountered above continue to behave like process/activity verbs after weiter has been attached, and that means that the accusative case of their direct objects has to be licensed in whatever way the accusative case of other transitive process/activity verbs is licensed. Our account so far says that if verbs have accusative objects, there must be [telic], and consequently, a culmination requirement is eventually imposed. This allows [telic] to combine with a large class of VPs. There is still a large class of verbs, however, that can't seem to combine with [telic] on the current account.

Take the VP schlep your suitcase. When you schlep a suitcase, the part structure of the suitcase does not provide a suitable measure for the success of your action. More importantly, suitcases that are being schlepped do not provide bounds for whatever possible measures of success there are, like the paths traveled or the schlepping times. Bounds for those measures have to be expressed by separate measure phrases, as in schlep your suitcase 50 yards or schlep your baby for two hours. Let us investigate, then, what happens when transitive process or activity verbs appear with a durational adverbial, as in (32). 
(32) Ich musste einen Tag (lang) deinen Koffer schleppen.

I had to one-acc day (long) your-acc suitcase schlep

I had to schlep a suitcase for one day.

If a verb is modified by a measure or degree phrase, it is that very phrase that provides the measure for the success of the event. (32) as a whole, then, is a telic construction where the phrase that provides the upper bound for the relevant scale is a measure phrase, rather than the direct object. Wechsler and Lee 1996 speak of 'situation delimiters' in those cases ${ }^{33}$. As emphasized by Wechsler and Lee, it cannot be an accident, that many languages use accusative case for measure and degree phrases, but not for other kinds of adjuncts.

When degree or measure phrases modify a VP in German, the whole construction becomes a multiple object construction. In contrast to English ${ }^{34}$, the syntax of measure phrases and other circumstantial adverbials is fairly straightforward in German. Scope relations are transparently reflected in the surface line-up. This is shown by the following example:

(33) Ich musste einen Monat lang jeden Tag eine Stunde Koffer schleppen. I had to one month long every day one hour suitcases schlep. I had to schlep suitcases for one hour every day for one month.

In (33), the order of circumstantial adverbials is fixed with respect to each other, and with respect to this kind of direct object, which is a weak indefinite. Any other order is unacceptable. The order we find in German is the one we expect from the point of view of LF-legibility. The English order needs to be explained - a project I can't pursue here.

33. Thanks to Min-Joo Kim for alerting me to Wechsler and Lee's paper.

34. See Cinque 1999, section 1.5 for discussion of this point. See also the remarks in Chomsky 1995, p. 333. 
We can now tentatively posit the following structure for the lower portion of sentence (32):

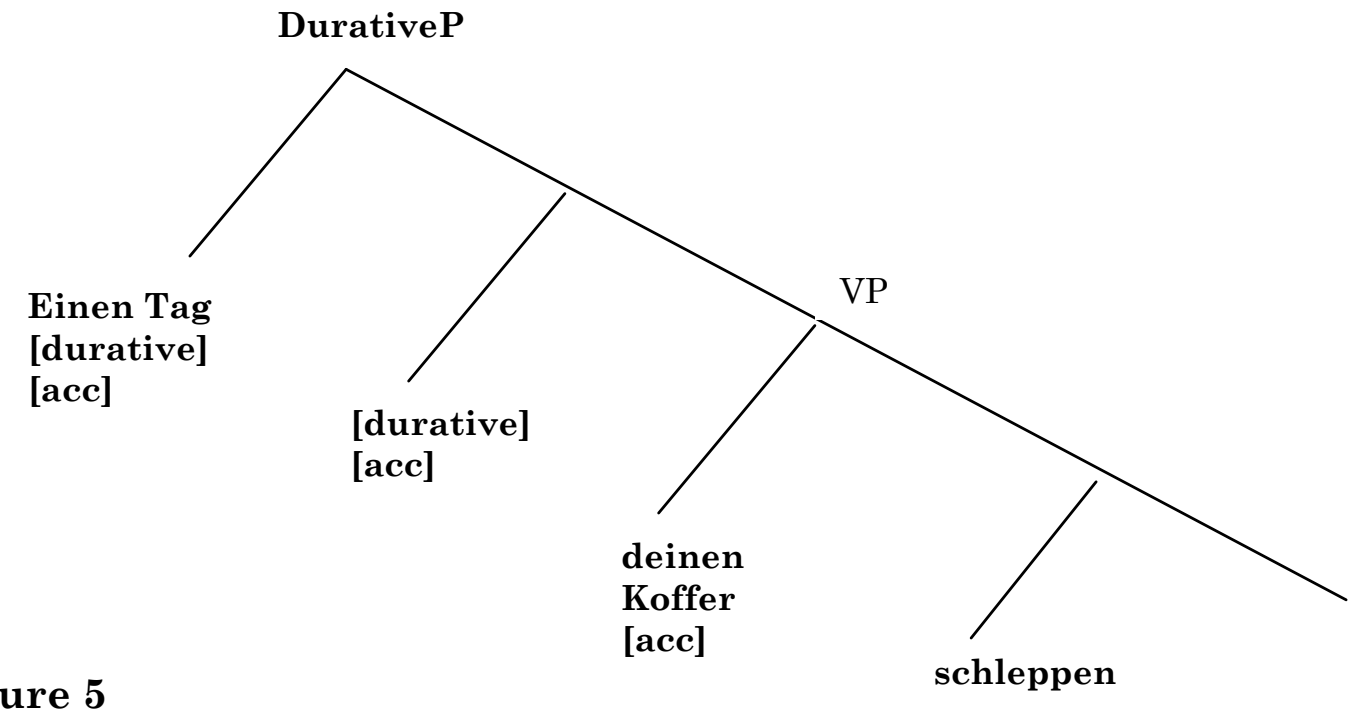

Figure 5

The structure in figure 5 is a two-headed shell structure. The direct object deinen Koffer ('your suitcase') is in the specifier position of the verb schleppen. Following Morzycki's program of Mediated Modification (2001, forthcoming), the measure phrase einen Tag ('one day') is placed in the specifier position of a functional head, which I assume to carry the interpretable feature [durative] ${ }^{35}$. The measure phrase itself is assumed to carry the uninterpretable version of the same feature, which might stay unpronounced or might be spelled out as the postposition lang (literally 'long') under conditions that do not have to concern us here. The fact that measure phrases are accusative marked in many languages suggests that their case is a candidate for nominal interpretable [acc]. German inherently delimiting DPs would

35. Morzycki uses the interpretable feature [+homogeneous], which has a slightly different denotation than my feature [durative], but the particular division of labor between functional head and measure phrase I am pursuing here was first proposed and defended in his work from a semantic point of view, following the syntactic lead of Cinque 1999. 
then carry semantic case. That they do is shown by the fact that they remain accusative marked in passive and unaccusative constructions ${ }^{36}$. Agreement with the accusative measure phrase in its specifier position makes it possible for the durative head to carry an instance of uninterpretable [acc] in addition to [durative]. The direct object deinen Koffer can now in turn enter an agreement relationship with that head. I am assuming that DPs that are not durational phrases are not the kind of categories that can have the feature [durative], hence agreement between the durative head and the direct object deinen Koffer can be established on the basis of [acc] alone. The checking relations are now as follows: Uninterpretable [acc] on the direct object deinen Koffer can be checked via agreement with uninterpretable [acc] on the durative head, and that feature in turn can be checked via agreement with the interpretable [acc] feature of the measure phrase. We have a phenomenon of 'telic concord', then, that looks very much like the more familiar phenomenon of negative concord.

After deletion of all uninterpretable features, the meaning of the relevant part of sentence (32) can be derived as follows ${ }^{37}$ :

deinen Koffer schleppen

[durative] \e schlep(your suitcase)(e)

$\square \mathrm{P} \square \mathrm{e}\left[\mathrm{P}(\mathrm{e}) \& \mathrm{e}=\square \mathrm{e}^{\prime}\left[\mathrm{P}\left(\mathrm{e}^{\prime}\right) \& \mathrm{e} \mathrm{e}^{\prime} \mathrm{e}\right]\right]^{38}$

36. As discussed by Wechsler and Lee 1996, the situation in Korean is more complicated. There are some durative adverbials that have inherent accusative. But generally, situation delimiting adverbials show up with nominative case in passive constructions, suggesting that a verbal inflectional head is involved.

37. No displacement of the direct object is necessary in this case. It can be interpreted in situ. This consequence should in principle be detectable. Under the right conditions, the direct objects of process and activity verbs should appear lower in the tree than the direct objects of accomplishment and achievement verbs. Direct confirmation of this prediction is difficult in German, Scottish Gaelic might be a more suitable language to look at. See Ramchand 1997. 
$\begin{array}{ll}\text { [durative](deinen Koffer schleppen) } & \square \mathrm{e}[\operatorname{schlep}(\text { your suitcase) }(\mathrm{e}) \& \mathrm{e}= \\ & \left.\square \mathrm{e}^{\prime}\left[\operatorname{schlep}(\text { your suitcase })\left(\mathrm{e}^{\prime}\right) \& \mathrm{e}^{\prime}<\mathrm{e}\right]\right]\end{array}$

Subevents of an event e cannot last longer than e itself, and that means that duration is monotonic with respect to the part-whole structure of events. Following the reasoning in Schwarzschild 2002, this monotonicity property is what forces modification of VPs by durational phrases to be mediated by inflectional heads that eliminate atomic events from the original VP denotations ${ }^{39}$. Applied to the VP in our example, the feature [durative] creates a property that is true of any event that is a schlepping of your suitcase and is made up of proper subevents of the same kind. The denotation of the durational phrase in (32) can be computed as follows:

$\begin{array}{ll}1 \text { day } & \square \mathrm{t} 1 \mathrm{day}(\mathrm{t}) \\ {[\operatorname{acc}]_{\mathrm{N}}} & \square \mathrm{Q} \square \mathrm{e} \mathrm{Q}(\square(\mathrm{e})) \\ {[\operatorname{acc}]_{\mathrm{N}}(1 d a y)} & \square \mathrm{e} 1 \mathrm{day}(\square(\mathrm{e}))\end{array}$

1 day denotes a property of times that is true of any time interval just in case it lasts for 1 day $^{40}$. The nominal interpretable feature [acc] applies to properties of

38. I am assuming that verb denotations are cumulative from the very start (Landman 2000, Kratzer (forthcoming)). Consequently, the VP denotation \e climb(Mount Monadnock)(e), for example, can be true of singular and plural events of climbing Mount Monadnock. Since all verb denotations start out cumulative, no $\mathrm{f}$-operator is necessary to indicate initial cumulativity. The feature [durative] maps the original VP-denotation into one that can only be true of plural climbs of Mount Monadnock.

39. Krifka 1998 has related observations. However, rather than monotonicity, Krifka takes the fact that measure phrases like two pounds denote extensive measure functions to be the relevant property that distinguishes between two pounds of meat and *two carats of gold or *two pounds of baby.

40. The function $\square$ is a temporal trace function that assigns to any event that has a temporal extension its temporal extension, a time interval. The meta-language predicate '1day' denotes a 
times and produces a property of events that last one day. Putting all the pieces together, the structure in figure 5 describes events of schlepping your suitcase that last one day.

An interesting consequence of the account of durational adverbials adopted here is that it does not prevent those adverbials from operating over telic VPs, as long as those VPs do not denote quantized properties of events. We therefore expect VPs that are built from a telic verb and a bare plural accusative object to be compatible with higher durational adverbials, while at the same time implying culmination. Example 5(a) from above showed already that this expectation is borne out.

a. Sie hat tagelang Fausthandschuhe gestrickt. She has for days mittens - Acc knit. She knit mittens for days.

Even though it implies culmination, the constituent consisting of [telic] and the VP knit mittens denotes a non-quantized property of events, hence can in turn combine with [durative] ${ }^{41}$.

What the VP knit mittens can't do, however, is use [durative] to license the accusative case of its direct object, and thus get around the culmination requirement. Quite generally, the direct objects of certain initially atelic VPs can't have their [acc] feature checked by any other head but [telic]. VPs headed by verbs of creation are in this category, for example, but also VPs like climb Mount Monadnock. Those VPs can't choose to stay atelic by skipping [telic] and picking

property of time intervals that is true of any time interval just in case it is a 1 day interval. See Schwarzschild 2002 for how to generalize this kind of denotation to other types of measure phrases.

41. The approach to telicity advocated here also seems to help with the Slavic quantization puzzles presented in Filip 2000. Since telicity itself is not necessary linked to quantization on the present proposal, the durative head is expected to be able to operate over telic VPs that do not denote quantized properties of events. 
[durative] instead. Why is that? We cannot invoke Maximize Interpretability as we did for Finnish. For speakers of German or English, too, the wish to avoid a commitment to culmination should be a legitimate reason to pick uninterpretable [acc] over [telic] to license the accusative of a direct object. There is a difference between the Finnish and the German or English situation, however. Suppose a minimal VP corresponding to climb Mount Monadnock is being built. As soon as the direct object has been introduced, the question of how its case feature is to be checked comes up. Speakers of Finnish have a choice between [telic] and uninterpretable [partitive] at that point. The choice has an impact on interpretation, but the impact is local and only affects the meaning of the VP that has just been built. If speakers of German or English chose uninterpretable [acc] to check the accusative case feature of the DP Mount Monadnock in the VP climb Mount Monadnock, they would have to commit themselves to merging a durational phrase, too, assuming, as we have, that the uninterpretable [acc] feature on [durative] must be checked by the interpretable [acc] feature of a durational phrase. In German or English, then, choosing uninterpretable [acc] to check accusative on a direct object carries a commitment to a future phase in the derivation. If we assume that that kind of look-ahead is dispreferred and only allowed as a last resort, it follows that in German or English, [telic] must be used to check accusative case features of direct objects whenever possible. We now correctly predict that climb Mount Monadnock for 10 years describes pluralities of culminated events of climbing Mount Monadnock.

There is still a problem, however. Look at the difference between 36(a) and (b):

(36) a. He climbed Mount Monadnock for 10 years.

b. He examined the patient for 30 minutes.

How come 36(a) can only describe pluralities of culminated events of climbing Mount Monadnock, whereas 36(b) can also describe a single, possibly incomplete, 
physical exam? The behavior of examine we see in 36(b) is shared by all verbs listed in (10) above. We have, for example:
a. He roasted the pig for 5 hours.
b. I cleaned the house for 5 hours.
c. You explained the painting to us for 5 hours.

Sentences 37(a) to (c) can all be true of singular actions that lasted for 5 hours and might not have culminated. There is a difference between verbs like examine, roast, clean, explain, then, and verbs like climb, eat, cross, knit, whose transitive uses imply culmination. Where could that difference come from if both types of verbs are built from atelic stems?

The difference seems to boil down to the fact that the direct object referents of examine-type verbs do not provide upper bounds for whatever scales might be associated with them. When doctors examine patients, the patients' bodies, say, do not define what it means to complete the job. The doctors might have to take a closer look at an ear, listen one more time to a heartbeat, or perform yet another battery of tests. When you clean a house, completion is again not necessarily a matter of cleaning all of its parts. The degree of cleanliness may play a role, too. When a museum guide explains a painting, there is more to it than covering all of its relevant parts. And when a pig is being roasted, there isn't an obvious final stage it has to reach. Examine-type verbs can't combine with [telic], then. They are in the same situation as run-of-the-mill atelic verbs in that respect. They must find an alternative way of checking the uninterpretable case feature of their direct objects. Non-overt measure or degree phrases are obvious solutions ${ }^{42}$, since they have to be posited in other areas of the grammar, too. The projections of gradable adjectives

\footnotetext{
42. See Kennedy and McNally 1999, and Hay, Kennedy, and Levin 1999 for closely related proposals.
} 
like tall, for example, are usually assumed to contain a possibly non-overt degree phrase providing a standard value for tallness ${ }^{43}$. On the current account, non-overt measure or degree phrases would be necessary whenever transitive verbs are not delimited by their direct object or an overt measure or degree phrase. In the absence of contextual information providing a standard value, an indefinite degree or measure phrase would have to be posited, requiring no more than some amount of schlepping your suitcase for the VP schlep your suitcase, for example. Like durational adverbials, non-overt measure or degree phrases carry interpretable accusative case features and can thus participate in telic concord and help with checking the uninterpretable [acc] feature of non-delimiting direct objects of transitive verbs ${ }^{44}$.

According to the analysis I am proposing, then, all events that are describable by the lower portions of a transitive verb's extended projection have to be delimited overtly or covertly in German, since accusative is the only objective case in the language. An important consequence of having obligatory delimiters is that their presence seems to exclude talk about ongoing events at that stage of the syntactic derivation. As has often been observed, atelic VPs like schlep your suitcase resemble mass nouns in that whenever they are true of an event, they are also true of all of its subevents. Those VPs have the subevent property, then. The introduction of a delimiter creates a predicate that doesn't have the subevent property any longer. Interestingly, and for reasons that I cannot go into here, the subevent property

43. According to Kennedy 1999, degree phrases are introduced by functional heads that are part of the adjective's extended projection. Morzycki's analysis of measure phrases is in the same spirit. According to Morzycki, measure phrases are introduced by functional heads that are part of the extended projection of verbs.

44. If the context of use provides a standard value, modification with phrases like in 5 hours seems to become possible, as in He roasted the pig in 5 hours or I cleaned the house in 2 days. More research is needed to figure out the exact semantics of phrases like in 5 hours. 
doesn't survive even if the delimiting phrase is an indefinite like some time, some distance, some amount, a little bit or what have you. There is something wrong with the sentence I played the violin a little bit for 5 months, for example. As soon as initially atelic VPs are delimited, then, they seem to describe maximal, hence completed, events of the relevant kind. To represent events as only partially realized - and thus still in progress during the reference time - an imperfective operator has to be introduced in the next phase of the derivation. If that operator was overt in German, we would actually see that run-of-the-mill atelic VPs come with possibly non-overt delimiters. Luckily, English happens to be a language that has an overt imperfective operator. For the following sentences, imagine again a cell phone conversation:
a. What are you doing? I am schlepping your suitcase.
b. * What are you doing? I schlep your suitcase.

Given that an atelic bare VP like schlep your suitcase has the subevent property, it is in fact quite surprising that we have to use the progressive when talking about ongoing schlepping actions. If the VP schlep your suitcase needs a measure or degree phrase to check the case of its object, we have a possible explanation for why 38 (b) is deviant ${ }^{45}$. 38(b) attempts to say that there is a maximal, hence completed, event of schlepping your suitcase at the utterance time. But then that schlepping event cannot possibly be an ongoing event. To talk about ongoing events, speakers of English must use the progressive, then, even if those events are activities or processes.

The analysis I proposed makes a rather strong prediction for unaccusatives in the relevant languages. There shouldn't be any telic ones that are built from atelic

\footnotetext{
45. The progressive must be used to describe ongoing events even when there is no accusative direct object. It seems, then, that an implicit delimiter has to be present in those cases, too.
} 
stems. As for German, the actual prediction is that you shouldn't find any unaccusatives that are compatible with weiter, but come out as unambiguously telic in the standard tests. The prediction seems to be borne out. McClure 1995 already argued that unaccusatives in Italian are either statives or achievement verbs ${ }^{46}$. German unaccusatives also include verbs describing activities like marschieren ('march'), fliegen ('fly'), or gleiten ('glide') ${ }^{47}$. In addition, there is a large number of unaccusatives that are "degree achievement verbs" in the terminology of Dowty 1979, a misnomer, as Hay, Kennedy, and Levin point out. Examples of degree achievement verbs are wachsen ('grow'), or fallen ('fall'). Degree achievement verbs combine with degree and measure phrases, of course (grow 2 inches, fall 100 yards) ${ }^{48}$, and are thus process/activity verbs on the present account. They are not classified as unambiguously telic by the standard tests. If they seem to imply culmination, that impression is due to the implicit presence of a degree or measure phrase specifying a standard value. The remaining German unaccusatives are statives (e.g. bleiben ('stay')) or verbs built from stems that already imply culmination. That last group of verbs can be easily identified since they do not combine with weiter, as shown by 39 (a) to (d):

46. See also Van Valin 1990.

47. Standard German differs from both Italian and Dutch in using the auxiliary sein even in constructions like Er ist stundenlang im Kreis herummarschiert ('He marched around in circles for hours'). The existence of the past participle construction die stundenlang im Kreis herummarschierten Soldaten ('the for hours in circles marched around soldiers', meaning 'the soldiers who marched around in circles for hours') shows that this is not merely an idiosyncrasy of auxiliary selection. Other examples: Er ist im Wald spazierengegangen ('he walked in the wood'), sie $\underline{\text { ist }}$ auf und ab gesprungen ('she jumped up and down'), er ist hin und her geflogen ('he flew back and forth'), er ist stundenlang über das Eis geglitten ('he glided over the ice for hours') etc. That unaccusativity is not universally linked to telicity is documented in Mithun 1991.

48. Hay, Kennedy and Levin 1999. 
a. * Sie ist weiterverreist.

She is on-went-on a trip.

'She continued to go on a trip'

b. * Hans ist weiteraufgewacht.

Hans is on- woken- up.

'Hans continued to wake up.'

c. * Maria ist weiterertrunken.

Maria is on- drowned.

'Maria continued to drown.'

d. * Das Schiff ist weiteruntergegangen.

The ship is on- under-went.

'The ship continued to go under.'

It is time to draw this chapter to a conclusion. While many important questions remain ${ }^{49}$, we have encountered some rather subtle facts suggesting that the visible connection between telicity and accusative case we find in Finnish might also exist in German and English. We speculated about how a German child might build a grammar that has a single objective case, and in the course of that investigation, we were able to connect a number of apparently unrelated phenomena in the area of Aktionsarten, case, and viewpoint aspect. The proposal I made about the connection between telicity and accusative case in German and English generates strong predictions that I hope will inspire typological and acquisition studies even if the actual expectations should eventually be disconfirmed. Minimally, I designed a

49. I haven't addressed what happens when accomplishment verbs are passivized. While there is no overt DP that carries accusative case in English passives, accusative case might nevertheless be present, as argued in Baker, Johnson, and Roberts 1989. This would still not explain why it isn't the delimiting argument that carries accusative case in English passives. A detailed morphological analysis of past participles is necessary to answer this question, which I have to leave open here. See Kratzer (forthcoming). Another important question I will have to leave for further research is what happens under negation. The objects of negated verbs have obligatory partitive case in Finnish. 
hypothetical scenario showing how superficially very different representations of case and aspect can be constructed by the minds of children working with the same grammar extraction kits.

\section{References}

Baker, Mark, Kyle Johnson, and Ian Roberts: "Passive Arguments Raised." Linguistic Inquiry 20, 1989, 219-252.

Bennett, Michael \& Barbara Partee: Toward the Logic of Tense and Aspect in English. Bloomington (Indiana University Linguistics Club), 1978.

Cinque, Guglielmo: Adverbs and Functional Heads. A Cross-Linguistic Perspective. New York (Oxford University Press), 1999.

Collins, Chris: Local Economy. Cambridge/Mass. (MIT Press), 1997.

Chomsky, Noam: The Minimalist Program. Cambridge/MA (MIT Press), 1995.

Chomsky, Noam: "Derivation by Phase". In M. Kenstowicz (ed.): Ken Hale. $\underline{\text { A Life }}$ in Language. Cambridge/MA (MIT Press), 2001.

Dowty, David: Word Meaning and Montague Grammar. Dordrecht (Reidel), 1979.

Dowty, David: “Thematic Proto-Roles and Argument Selection.” Language 67 (1991), 547-619.

Filip, Hana: "The Quantization Puzzle”. In C. Tenny and J. Pustejovsky (eds.): Events as Grammatical Objects. The Converging Perspectives of Lexical Semantics and Syntax. Stanford (CSLI Publications), 2000, $39-96$.

Hay, Jen, Christopher Kennedy \& Beth Levin: "Scale Structure underlies telicity in 'degree achievements'”. In Proceedings of SALT IX, Ithaca/N.Y. (CLC Publications), 1999, 127-144.

Heim, Irene \& Angelika Kratzer: Semantics in Generative Grammar. Oxford (Blackwell), 1998.

Kennedy, Christopher: Projecting the Adjective. The Syntax and Semantics of Gradability and Comparison. New York (Garland), 1999.

Kennedy Christopher \& Louise McNally: "From event structure to scale structure." In Proceedings of SALT IX, Ithaca/N.Y. (CLC Publications), 163-180. 
Kiparsky, Paul: "Partitive Case and Aspect". In M. Butt and W. Geuder (eds.): The Projection of Arguments. Stanford (CSLI Publications), 1998, 265-307.

Kratzer, Angelika: "Severing the External Argument from its Verb". In J. Rooryck \& L. Zaring (eds.): Phrase Structure and the Lexicon. Dordrecht (Kluwer), 1996, 109-137.

Kratzer, Angelika: "Building Statives.” In Lisa J. Conathan et al. (eds.): Proceedings of the 26th Annual Meeting of the Berkeley Linguistics Society, Berkeley 2000, 385-399.

Kratzer, Angelika: The Event Argument and the Semantics of Voice. Cambridge/Mass. (The MIT Press), forthcoming.

Krifka, Manfred: "Nominal Reference, Temporal Constitution and Quantification in Event Semantics.” In R. Bartsch, J. von Benthem, and P. van Emde Boas (eds.): Semantics and Contextual Expression. Dordrecht (Foris), 1989, 75-115.

Krifka, Manfred: "Thematic Relations as Links between Nominal Reference and Temporal Constitution.” In Ivan Sag \& Anna Szabolcsi (eds.): Lexical Matters. Stanford (CSLI Publications), 1992, 29-53.

Krifka, Manfred: "The Origins of Telicity". In S. Rothstein (ed.): Events and Grammar. Dordrecht (Kluwer), 1998, 197-235.

Landman, Fred: Events and Plurality. The Jerusalem Lectures. Dordrecht (Kluwer), 2000.

Levin, Beth: "Aspect, Lexical Semantic Representation, and Argument Expression". In Lisa J. Conathan et al. (eds.): Proceedings of the 26th Annual Meeting of the Berkeley Linguistics Society, Berkeley 2000, 413-429.

Marantz, Alec: On the Nature of Grammatical Relations. Cambridge/MA (The MIT Press), 1984.

McClure, William: Syntactic Projections of the Semantics of Aspect. Cornell University Ph.D. Dissertation, 1994.

Mithun, Marianne: “Active/Agentive Case Marking and its Motivation.” Language $67,1991,510-546$. 
Moltmann, Friederike: Parts and Wholes in Semantics. Oxford (Oxford University Press), 1996.

Morzycki, Marcin: "Interpreting Measure DP Adverbials." Talk presented at WCCFL XX, University of Southern California, 2001.

Morzycky, Marcin: Modifier Interpretation and Functional Structure. UMass Ph.D. dissertation (forthcoming).

Parsons, Terence: Events in the Semantics of English. Cambridge/MA. (The MIT Press), 1990.

Pesetsky, David \& Esther Torrego: "T-to-C Movement: Causes and Consequences". In: Ken Hale. A Life in Language. Cambridge/MA (The MIT Press), 2001, 355-426.

Pylkkänen, Liina: Introducing Arguments. MIT Ph.D. Dissertation, 2002.

Ramchand, Gillian Catriona: Aspect and Predication. The Semantics of Argument Structure. Oxford (Clarendon Press), 1997.

Schwarzschild, Roger: "The Grammar of Measurement." In B. Jackson (ed.):

Proceedings of SALT XII. Ithaca/N.Y., (CLC Publications), 2002.

Smith, Carlota: The Parameter of Aspect. Dordrecht (Kluwer), 1991.

Singh, Mona: "On the Semantics of the Perfective Aspect". Natural Language

Semantics 6 (1998), 171-199.

Streitberg, W.: "Perfective und imperfective Actionsart im Germanischen." Beiträge zur Geschichte der deutschen Sprache und Literatur 15, 7 - 177.

Tenny, Carol: Grammaticalizing Aspect. MIT PhD Dissertation, 1987.

Tenny, Carol: Aspectual Roles and the Syntax-Semantics Interface. Dordrecht (Kluwer), 1994.

Vainikka, Anne: Deriving Syntactic Representations in Finnish. UMass

Dissertation, 1989.

Van Valin, Robert: "Semantic Parameters of Split Intransitivity". Language 66, 221 -260 .

Wechsler, Stephen and Yae-Sheik Lee: "The Domain of Direct Case Assignment". Natural Language and Linguistic Theory 14, 1996, 629-664. 
Zimmermann, Thomas E.: "On the Proper Treatment of Opacity in Certain Verbs." Natural Language Semantics 1, 1995, 33-78.

Zucchi, Alessandro: "Incomplete Events, Intensionality and Imperfective Aspect." Natural Language Semantics 7(2), 1999, 179-215. 